\title{
Investigation of Some Nonionic Surfactants as Corrosion Inhibitors for Carbon Steel in Sulfuric Acid Medium
}

\author{
Florina Branzoi ${ }^{1, *}$ and Viorel Branzoi ${ }^{2}$ \\ ${ }^{1}$ Institute of Physical Chemistry, 202 Splaiul Independenţei, Bucharest, Romania, \\ ${ }^{2}$ University Politehnica of Bucharest, 132 Calea Griviţei, Bucharest, Romania, \\ *E-mail fbrinzoi@ chimfiz.icf.ro
}

doi: $10.20964 / 2017.08 .27$

Received: 7 April 2017 / Accepted: 29 May 2017 / Published: 12 July 2017

Four nonionic surfactants have been investigated as corrosion inhibitors for carbon steel type OL37 in sulfuric acid solution by electrochemical methods, FT-IR spectroscopy and metallurgical microscopy techniques. The influence of inhibitor concentration on the corrosion rate, inhibition effectiveness and surface coverage was analyzed. Results indicate that these surfactants accomplish a great inhibiting action on carbon steel corrosion and acts that a mixed-type inhibitor. The inhibition effect of noionic surfactants may be due to either the adsorption of inhibitor molecules building a protective layer or the constitution of an insoluble complex of the inhibitor adsorption obeys the Langmuir model. The negative value of thermodynamic parameter like Gibbs free energy of adsorption $\Delta G_{a d s}^{\circ}$ indicates the spontaneity of adsorption process. Moreover, characterization utilizing FT-IR confirms the adsorption of inhibitors and the constitution of corrosion products on the carbon steel surface. EIS and potentiodynamic polarization results demonstrate its corrosion protection capacity.

Keywords: organic inhibitor, nonionic surfactant, carbon steel, potentiodynamic polarization, electrochemical impedance spectroscopy and FT-IR.

\section{$\underline{\text { FULL TEXT }}$}

(C) 2017 The Authors. Published by ESG (www.electrochemsci.org). This article is an open access article distributed under the terms and conditions of the Creative Commons Attribution license (http://creativecommons.org/licenses/by/4.0/). 